Abstract 105 Table 1 Characteristics of patients presenting with ACS

\begin{tabular}{ll} 
Demographics & $\mathrm{n}=25,287$ \\
\hline Mean age (years) & $66.6(14.3)$ \\
Male & $16,227(64.2 \%)$ \\
Female & $9060(35.8 \%)$ \\
Ethnicity & \\
Caucasian & $20,302(80.3 \%)$ \\
South Asian & $1622(6.4 \%)$ \\
Afro-Caribbean & $197(0.8 \%)$ \\
Oriental & $51(0.2 \%)$ \\
Mixed & $48(0.2 \%)$ \\
Other & $357(1.4 \%)$ \\
Unknown & $2710(10.7 \%)$ \\
Mean LoS (days) & $7(16.2)$ \\
Deaths & $9653(38.2 \%)$ \\
\hline Data are number (\%) or mean (SD).
\end{tabular}

concomitant cardiovascular diseases were associated with an increased LOS and mortality: PVD (8.6 days, $\mathrm{P}<0.05 ; 53 \%$ OR 1.93 [95\% CI 1.68-2.21], P < 0.001), AF (10.9 days;
63.5\% OR 1.51 [95\% CI 1.38-1.66], P < 0.001), Cerebrovascular disease $(15.9$ days; $76 \%$ OR 2.29 [95\% CI $1.67-$ 3.15], $\mathrm{P}<0.001)$, HF (11 days; 69.9\% OR 3.28 [95\% CI 3.03-3.56], $\mathrm{P}<0.001)$, and IHD (6.7 days, $\mathrm{P}<0.001$; $38.7 \%$ OR 1.16 [95\% CI 1.06-1.26], P < 0.05).

Conclusion Cardiovascular risk factors and concomitant disease have a significant impact on LOS and mortality in patients presenting with MI. The presence of these diseases should be used to identify patients at an increased risk of prolonged admissions and death post MI, and services should be directed accordingly.

\section{Interventional Cardiology}

\section{CARDIOVASCULAR DISEASE OUTCOMES STRATEGY DRIVES IMPROVED SURVIVAL FOR PATIENTS WITH OUT- OF-HOSPITAL CARDIAC ARREST}

Shona Johnson*, Stephanie Horne, Tracey Realey, Liza Keating, William Orr. Royal Berkshire Hospital; *Presenting Author

\subsection{6/heartjnl-2016-309890.106}

Background NHS statistics show that Emergency Medical Services (EMS) attend nearly 60000 patients with out-of-hospital cardiac arrest (OOHCA) in England each year and attempt cardiopulmonary resuscitation (CPR) in approximately 28000 cases. The chances of survival are improved by an immediate call for help, early bystander CPR and defibrillation, rapid

\begin{tabular}{|c|c|c|c|c|c|}
\hline $\begin{array}{l}\text { Cardiovascular } \\
\text { Disease/Risk } \\
\text { Factors }\end{array}$ & $N(\%)$ & $\begin{array}{l}\text { Mean } \\
\text { LOS } \\
\text { (days) }\end{array}$ & $\begin{array}{c}\text { ODDs ratio for Length } \\
\text { of stay }\end{array}$ & $\begin{array}{c}\text { Crude number } \\
\text { of deaths } \\
\text { (\% mortality) }\end{array}$ & $\begin{array}{c}\text { ODDs ratio for } \\
\text { mortality post } \mathrm{AMI}\end{array}$ \\
\hline Hypertension & $\begin{array}{r}11,393 \\
(45.1)\end{array}$ & 7.0 & $0.997^{\ddagger}(0.995-0.999)$ & $4197(36.8)$ & $0.717^{\ddagger}(0.671-0.765)$ \\
\hline Hyperlipidaemia & $\begin{array}{r}6274 \\
(24.8)\end{array}$ & 4.8 & $0.982 \ddagger(0.979-0.985)$ & $1214(19.4)$ & $0.423^{\ddagger}(0.390-0.459)$ \\
\hline T2DM & $\begin{array}{r}4758 \\
(18.8)\end{array}$ & 7.8 & $1.003^{*}(1.001-1.004)$ & $2112(44.4)$ & $1.304^{\ddagger}(1.204-1.411)$ \\
\hline T1DM & $698(2.8)$ & 7.0 & $1.001(0.998-1.005)$ & $288(41.3)$ & $1.674^{\ddagger}(1.396-2.007)$ \\
\hline Angina & $\begin{array}{r}8079 \\
(31.9)\end{array}$ & 5.4 & $0.983^{\ddagger}(0.980-0.985)$ & $2705(33.5)$ & $0.746^{\ddagger}(0.679-0.819)$ \\
\hline PVD & $1285(5.1)$ & 8.6 & $1.003^{*}(1.000-1.005)$ & $681(53.0)$ & $1.926^{\ddagger}(1.681-2.207)$ \\
\hline $\mathrm{AF}$ & $\begin{array}{r}3484 \\
(13.8)\end{array}$ & 10.9 & $1.008^{\ddagger}(1.006-1.010)$ & $2211(63.5)$ & $1.514^{\ddagger}(1.384-1.656)$ \\
\hline CVD & $1312(5.2)$ & 15.9 & $1.016^{\ddagger}(1.014-1.018)$ & $997(76.0)$ & $2.293^{\ddagger}(1.671-3.145)$ \\
\hline Heart Failure & $\begin{array}{r}4665 \\
(18.4)\end{array}$ & 11.0 & $1.012^{\ddagger}(1.010-1.015)$ & $3259(69.9)$ & $3.281^{\neq}(3.025-3.559)$ \\
\hline IHD & $\begin{array}{r}12,363 \\
(48.9)\end{array}$ & 6.7 & $0.996^{\ddagger}(0.994-0.998)$ & $4783(38.7)$ & $1.159 *(1.062-1.264)$ \\
\hline
\end{tabular}

T2DM, type 2 diabetes mellitus; T1DM, type 1 diabetes mellitus; PVD, peripheral vascular disease; AF, atrial fibrillation; CVD, cerebrovascular disease; IHD, ischaemic heart disease.

a Adjusted for age, sex, and ethnicity.

* Statistically significant, $\mathrm{p}<0.05$.

₹ Statistically significant, $p<0.001$. 


\begin{tabular}{llll} 
Abstract 106 Table 1 & & \\
\hline & $\begin{array}{l}\text { National Data Oct '12 - } \\
\text { May '15 }\end{array}$ & $\begin{array}{l}\text { OOHCA } \\
\text { Survival } \\
\text { to } \\
\text { discharge }\end{array}$ \\
\hline & $n$ & & $\%$ \\
England & 79618 & $n$ & $\% .4$ \\
South Central Ambulance Service & 3428 & 6672 & 8.4 \\
(SCAS) & & 595 & $17.4^{*}$ \\
Royal Berkshire Hospital (RBH) & 493 & 96 & $19.5^{*}$ \\
& & & $* *$ \\
\hline${ }^{*} p<0.001$ v England ${ }^{* *} \mathrm{p}=\mathrm{ns}$ v SCAS & &
\end{tabular}

transfer to hospital and early access to intensive care, 24/7 emergency coronary intervention when indicated and other supportive measures. The Cardiovascular Disease Outcomes Strategy calls for a range of measures across this pathway that will lead to improved survival rates in the UK. This triggered a series of local public education initiatives, closer working between the ambulance service, emergency department (ED), cardiology and intensive care, and a new protocol for these patients delivering more aggressive use of angiography and PCI in order to achieve better outcomes.

Method We analysed ambulance service data, ED records, local MINAP and Trust coding data to identify 3428 patients over 32 months who presented with OOHCA in our catchment area (population c.550 000), in whom CPR was started or continued, and who survived to arrival at hospital. Outcomes in hospital were recorded for each patient and compared with NHS England statistics.

Results $22 \%$ of patients arriving at $\mathrm{RBH}$ with OOHCA went to the cath lab with $62.4 \%$ survival $\mathrm{v} 7.3 \%$ for the rest $(\mathrm{p}<$ 0.001). $49 \%$ of patients transferred to the cath lab underwent PCI (no difference in rates between admission routes) with a trend towards better survival rates compared to those undergoing angiography alone $(67.7 \%$ v 50\%, ns).

Conclusions Patients with OOHCA treated by South Central Ambulance Service (SCAS) have a significantly better chance of survival to discharge than the average for England with a trend towards even better survival at our hospital. This difference may be due to our targeted working with SCAS on pathways for OOHCA and the high likelihood across this region of patients being taken directly to a heart attack centre. Patients requiring airway management or ongoing CPR on arrival at $\mathrm{RBH}$ are taken to $\mathrm{ED}$ for stabilisation prior to cath lab transfer, but the mortality of those coming to the cath lab via this route with the additional delay is not statistically different from those with direct admission. Patients who present to our hospital with out-of-hospital cardiac arrest and survive

\begin{tabular}{llll} 
Abstract 106 Table 2 & & \\
\hline Royal Berkshire Hospital Oct '12 - May '15 & & \multicolumn{2}{l}{ Survival to discharge } \\
\hline & $n$ & $n$ & $\%$ \\
Direct to Cath Lab & 46 & 31 & $67.4^{*}$ \\
ED discharge to Cath Lab & 63 & 37 & 58.7 \\
Total to Cath Lab & 109 & 68 & 62.4 \\
ED discharge no Cath Lab & 82 & 28 & $34.1^{\text {** }}$ \\
\hline
\end{tabular}

${ }^{*} p=n s \vee$ ED discharge to Cath Lab ${ }^{* *} p<0.05 \vee$ ED discharge to Cath Lab to the cath lab are a self-selecting group who, with current best care, have a very good chance of survival. Ongoing work will guide further refinement of these treatment pathways.

\section{Acute Coronary Syndromes}

\section{THE PREVALENCE, PREDICTORS AND OUTCOMES ASSOCIATED WITH ANAEMIA AMONG PATIENTS THAT PRESENT WITH ACS: INSIGHTS FROM THE UK MINAP REGISTRY}

${ }^{1}$ Chun Shing Kwok* ${ }^{1}$ 'Mamas A Mamas, ${ }^{2}$ Evangelos Kontopantelis, ${ }^{3}$ Anthony A Fryer, ${ }^{4}$ Iain Buchan, ${ }^{5}$ Max 0 Bachmann, ${ }^{5} \mathrm{M}$ Justin Zaman, ${ }^{6}$ Phyo K Myint. ${ }^{1}$ Keele University; ${ }^{2}$ University of Manchester; ${ }^{3}$ Royal Stoke University Hospital; ${ }^{4}$ Farr Institute; ${ }^{5}$ University of East Anglia; ${ }^{6}$ University of Aberdeen; *Presenting Author

\subsection{6/heartjnl-2016-309890.107}

Background Data from both registry and post-hoc analysis of randomised controlled trials have suggested that the burden of anaemia among patients admitted with acute coronary syndrome (ACS) is significant. However, current guidelines fail to offer firm recommendations for its concurrent management in the ACS settings.

Methods The Myocardial Ischemia National Audit Project (MINAP) registry collects data on all patients age 18 years or over who are admitted to all 230 NHS hospital trusts in England and Wales with a diagnosis of ACS. We conducted a retrospective cohort study for all ACS patients admitted on the MINAP registry between January 2006 to December 2010 and followed up these participants until August 2011 for mortality. Multiple logistic regression was used to calculate independent predictors of anaemia and the adjusted odds of 30day and 1-year mortality for anaemic and non-anaemic group. Additional analysis was performed evaluating the odds of mortality with incremental $1 \mathrm{~g} / \mathrm{dl}$ increase in haemoglobin.

Results A total of 422,855 participants with ACS were included in the analysis and $27.7 \%$ of these participants were anaemic. Anaemic participants were older (OR 1.046, 95\% CI 1.045-1.046) and had a greater prevalence of co-morbid conditions (renal disease (OR 3.06, 95\% CI 2.96-3.16), peripheral vascular disease (OR 1.43, 95\% CI 1.36-1.50), diabetes mellitus (OR 1.79, 95\% CI 1.74-1.83) and previous acute myocardial infarction (OR 1.21, 95\% CI 1.18-1.24)) and are less likely to receive evidence based therapies shown to improve clinical outcomes. Further analysis suggested that anaemia is independently associated with 30-day (OR 1.28, 95\% CI 1.22-1.35) and 1-year mortality (OR 1.31, 95\% CI 1.27-1.35). We observed a reverse J-shaped relationship between haemoglobin levels and mortality outcomes.

Conclusions In this largest study to date of anaemia in ACS, we report that approximately one in four patients presenting with ACS are anaemic and these patients are older with more co-morbid conditions and are less likely to receive evidence based therapies. Anaemic patients are also more likely to have adverse outcomes. Whilst the clinical effectiveness of correcting anaemia routinely in ACS has not been widely explored, there is considerable uncertainty in the value of such an approach. Targeted intervention strategies in this patient population should be explored. 